\title{
O uso da escrita na epigrafia latina
}

\author{
MARIA LUIZA CORASSIN \\ Departamento de História \\ Faculdade de Filosofia. Letras e Ciências Humanas \\ Universidade de São Paulo
}

\begin{abstract}
RESUMO: Roma conheceu múltiplos usos da escrita sob as mais diversas formas: uso público (textos políticos, administrativos, religiosos) mas também uso privado. A intensa utilização de inscrições constitui uma característica do mundo romano, "a civilização da epigrafia"; elas são inestimáveis documentos originais sobre a situação econômica e social romana.
\end{abstract}

PALAVRAS-CHAVE: Roma; escrita; epigrafia latina.

A mensagem epigráfica constituiu-se na forma de comunicação privilegiada na Antigüidade romana. Destinadas a atingir um público muito amplo, as inscrições eram de tipos bem mais variados do que as formas que são empregadas ainda hoje; muito do que atualmente se encontra em jornais, cartazes e arquivos, no mundo romano era gravado em pedra ou bronze. A epigrafia se insere no quadro geral dos estudos relativos ao mundo antigo como uma via especializada para seu conhecimento. O estudo das inscrições tem por objetivo a compreensão do mundo que as produziu, reunindo e estudando os textos escritos sobre variados materiais, como pedra, metal, argila, incluindo também os mosaicos, grafitos e inscrições pintadas; excetuam-se as inscrições a pena sobre papiro, pergaminho e as incisas em moedas. O suporte utilizado é com freqüência uma estela, especialmente talhada para este fim, sendo comum a incisão também na base de uma estátua, na lápide de um túmulo, em um monumento, no muro de um edifício - público, privado ou sacro.

O conhecimento epigráfico de inscrições latinas e também gregas é necessário para o pesquisador de história romana, especialmente aqueles que se dedicam ao período imperial; elas não são apenas um complemento precioso, mas em determinados aspectos constituem a documentação básica para conhecer situações não documentadas de outra forma. Certas peculiaridades do mundo antigo, que os historiadores clássicos não se preocuparam em registrar - pois eram de conhecimento óbvio para todos - e portanto estariam perdidas para nós, foram conservadas por intermédio das inscrições. Muitas vezes os autores antigos expressam os interesses e as opiniões do seu próprio grupo social; na maioria dos casos, da aristocracia. Em contraste com esta documentação textual, por vezes com lacunas, podemos contar com abundante informação epigráfica; existem milhares de inscrições latinas, cujo número aumenta continuamente, graças a novas descobertas em todas as partes do mundo romano. Uma simples vista de olhos pelo Corpus Inscriptionum Latinarum permite constatar a enorme quantidade de material escrito deixado pelo mundo romano; nele está reunida a produção escrita em material durável, sobretudo a pedra e o metal, deixando de lado obviamente a produção textual originalmente contida em códices e volumina. 
O uso das inscrições não se limitou aos grupos privilegiados da sociedade, mas era difundido em todos os níveis sociais. Por intermédio das inscrições podemos conhecer vários aspectos do mundo romano, encontrando-se documentação referente desde a imperadores até a humildes artesãos e escravos; informam sobre a titulatura imperial, a exata sucessão dos cargos e funções do cursus honorum das duas principais ordens, a senatorial e a eqüestre; fornecem também informações sobre cargos municipais ou dos escalões inferiores; ilustram a composição dos diferentes efetivos do exército, como as legiões, as coortes pretorianas, os corpos auxiliares, esclarecendo-nos sobre a hierarquia militar, as zonas de recrutamento, as modalidades de "aposentadoria" ao final do serviço. Muitas particularidades, como a concessão de cidadania aos soldados não romanos, que serviam nos corpos auxiliares do exército, podem ser estudadas graças aos “diplomas” (duas lâminas de metal), nome dado ao certificado fornecido ao interessado pelas autoridades como prova da aquisição da cidadania. Os miliários, marcos colocados a cada milha, como o nome indica, nos falam da rede viária romana e da manutenção das estradas pelo Estado. As lamparinas, as ânforas, os canos de chumbo dos aquedutos e os tijolos conservaram dados interessantes sobre a história econômica e até nomes de funcionários. Sobreviveram as tesserae destinadas à distribuição do trigo e as que serviam como ingresso para os espetáculos. As paredes das ruas apresentavam-se, como hoje, recobertas de escritos, especialmente em época de eleições, como os grafitos e as inscrições pintadas em Pompéia o comprovam. Os sarcófagos e os columbários estavam repletos de inscrições funerárias; muitas vezes estas dedicatórias fúnebres eram em forma de poesia. Todo este material constitui um conhecimento em primeira mão do mundo romano, permitindo reconstituir as relações sociais e familiares, e ter acesso aos círculos ligados aos espetáculos, às artes e às profissões.

Esta constatação nos remete para algumas questões: qual a medida da difusão da mensagem escrita no mundo romano? Qual o uso da escrita no espaço público? A qualidade do trabalho de elaboração das inscrições revela a existência de profissionais altamente habilitados, mas ao lado destes havia também outros de nível mais modesto, como indica a visível diferença qualitativa da produção lapidária. Ao lado da escrita originária de uma elita culta, ligada à literatura, havia certamente outra de cunho mais popular. Mireille Corbier (Corbier, 1987) destaca ainda a existência de um diálogo entre os donos do poder e a massa dos cidadãos e dos soldados, podendo ser neste caso seu uso considerado simultaneamente de elite e de massa. O local preferencial de divulgação desta mensagem é a praça pública. Em Roma a relação entre a escrita e o poder atinge seu ponto culminante, com os textos que a autoridade pública emite para conhecimento dos cidadãos e dos habitantes do império em geral. A principal preocupação é a manifestação do poder. A função epigráfica pressupõe a comunicação com o maior número de leitores e a durabilidade das inscrições. Isto explica o uso de letras monumentais no espaço público, sobretudo nos eixos de maior circulação. As inscrições em material durável eram afixadas de modo permanente nos fóruns e no Capitólio em Roma; são notáveis exemplos deste tipo de documento as listas dos Fastos consulares e as listas dos soldados veteranos que receberam privilégios. Nas demais cidades ocorria um processo semelhante: o álbum de Canúsio e o mármore de Thorigny conservaram os nomes dos homens notáveis da aristocracia de cada uma destas localidades.

O uso da escrita, e portanto da leitura, assumiu em Roma um aspecto original, pelo seu múltiplo uso público ou privado. Homens que por cultura ou profissão sabiam ler e escrever produziram literatura, corresponderam-se, cuidaram de arquivos públicos, redigiram atas de sessões do Senado e de reuniões de confrarias religiosas. Além destes usos da 
escrita, textos oficiais ou privados foram gravados e afixados em variados suportes, de modo a serem lidos por todos os passantes em lugares do espaço urbano e mesmo no prolongamento natural da cidade, ao longo das estradas. As inscrições constituíam parte da vida diária dos romanos. Os autores podiam ser homens públicos, (desde o imperador até funcionários subalternos encarregados da execução de serviços), privados (o dedicante de uma estátua ou de um sepulcro), ou membros de uma coletividade (Senado, conselhos municipais, colégios sacerdotais ou profissionais).

De imediato surge a pergunta: tratava-se de uma sociedade com alto nível de alfabetização? Para Corbier, é pouco provável que tal ocorresse na Roma imperial. A utilização intensiva de documentos epigráficos era compatível com um baixo nível de capacidade de leitura. Para o cidadão comum seria suficiente reconhecer as letras capitais, alguns nomes ou as letras maiúsculas para ler textos inscritos. A alfabetização do público masculino era bastante difundida, embora em nível elementar.

Apesar do grande número de epígrafes que sobreviveram e dos contínuos achados de novos exemplares, algumas só são conhecidas graças a cópias conservadas em outros locais ou nas províncias, embora seu texto fosse conhecido por citações em autores. Tito Lívio já mencionara a existência do senatus consultum de Bacchanalibus, o qual foi encontrado em uma inscrição contendo a carta dos cônsules do ano de 186 a.C. dirigida aos magistrados de uma localidade no sul da Itália, proibindo as associações destinadas ao culto dionisíaco. Do mesmo modo, Suetônio referiu-se ao conteúdo das Res Gestae de Augusto; embora o original do documento afixado em bronze diante do mausoléu de Augusto tenha desaparecido, conhecemos o texto latino e a tradução grega pelas cópias enviadas às províncias e encontradas em três cidades da Ásia Menor. Isto comprova a difusão da mensagem epigráfica e a amplitude do destinatário: o público romano e provincial. Outras inscrições chegaram até nós, embora fragmentárias, como as Atas das reuniões da confraria dos Arvais, afixadas em paredes do templo e em outros edifícios do local de culto da divindade agrícola Dea Dia, nas vizinhanças de Roma.

Aos soldados veteranos das tropas auxiliares era concedido o privilégio da cidadania romana; os originais afixados em Roma se perderam, mas os diplomas entregues a cada soldado contemplado com o privilégio sobreviveram em grande número; nestas cópias consta o local onde o original podia ser encontrado e conferido, o que garantia a autenticidade do documento apresentado pelo novo cidadão quando requisitado pelas autoridades.

O uso da escrita em documentação do tipo "oficial" era, portanto, institucionalizado; de modo geral, os habitantes do mundo greco-romano estavam habituados a ela; além disso, uma inscrição funerária estava ao alcance até mesmo de um simples escravo, desde que dispusesse de meios suficientes para deixar um registro de sua memória.

O alfabeto latino, como aqueles de outras línguas itálicas, derivou do alfabeto grego ocidental. Não podemos falar de uma escrita própria das epígrafes, mas de uma escrita latina que evoluiu em duas formas. Uma destas formas utilizadas pela epigrafia latina é a denominada "capital", tornando-se característica, embora não exclusiva, das epígrafes. A denominação foi criada pelos paleógrafos, porque era empregada nos "capita" dos manuscritos. A outra forma é a cursiva, ou a "comum" clássica, característica da escrita corrente empregada particularmente em papiros, pergaminhos e tabuinhas enceradas. Há exceções: existem inscrições funerárias, defixiones e grafitos em escrita cursiva, enquanto que papiros foram feitos em escrita capital.

A limitação do espaço em que a escrita devia ser colocada originou um estilo epigráfico: o dicionário registra como "estilo lapidar" o estilo conciso, sucinto, característi- 
co das inscrições comprimidas num espaço restrito. A tendência dominante é resumir o texto em proposições curtas, o que não impede a existência de inscrições longas, sejam elas honorárias ou funerárias. Estas últimas podem inclusive ser em versos; nestes casos, geralmente não são composições populares originais, mas cópias extraídas da literatura culta. No período do Império tardio, as inscrições imperiais ou honorárias tornam-se muito longas, com extensa titulatura e referências à generosidade do personagem; destoam da tradicional brevidade epigráfica e testemunham as novas relações sociais que se desenvolveram principalmente a partir do século IV, com a concentração do poder e o crescimento da conseqüente subserviência que transparece no estilo bajulatório geral.

A economia de espaço explica também o abundante uso de abreviaturas. Uma das dificuldades da leitura da mensagem epigráfica é desenvolver as abreviações que constituem sua característica marcante. Hoje as manchetes dos jornais e as capas das revistas estão repletas de siglas; do mesmo modo, no mundo romano esperava-se que o leitor comum entendesse o significado delas. Assim, IOM devia ser compreendido como Iuppiter Optimus Maximus, sem maiores dificuldades daquelas que hoje entender o significado de FMI oferece para o leitor dos cadernos de economia dos jornais.

A titulatura, as palavras de fórmulas constantemente usadas, mas por vezes também outras palavras, eram abreviadas. Assim, os prenomes mais comuns eram escritos abreviadamente: $C$ (aius), $L($ ucius $), M($ arcus $)$, por exemplo. Escreviam-se as primeiras letras, omitindo-se as finais da palavra; geralmente colocavam-se a primeira, ou as duas ou três primeiras letras; muitas vezes escrevia-se a palavra até uma consoante. Outras palavras eram abreviadas pelas consoantes, como populusque romanus por "PQR" e beneficiarius por "BF". O título de "cônsul" era abreviado por COS, devido a tendência em não se pronunciar o "N" antes do "S". Para indicar que um único título se referia a duas ou três pessoas, a consoante final ou a sigla era duplicada ou triplicada: AVGG NN por Augustorum Nostrorum ou DD NN por Domini Nostri. As contrações tornaram-se ainda mais frequientes no século $\mathrm{V}$ e nas inscrições cristãs. Outra característica da escrita epigráfica consiste na junção de duas ou mais letras capitais, como por exemplo AE, AV, NE, TI, TH ou RNE.

O latim das epígrafes, se excluirmos os textos jurídicos que apresentam características próprias, não oferece particularidades que dificultem sua interpretação. As epígrafes "oficiais", colocadas em espaço público pelas autoridades, são corretas tanto pela linguagem quanto pela execução bem cuidada, pois eram feitas pelos lapicidas mais competentes e experientes. Observamos no entanto uma defasagem entre o centro e a periferia do Império, pois as áreas mais afastadas tendiam a apresentar diferenças regionais na elaboração das inscrições em relação a Roma ou a zonas mais romanizadas.

Algumas categorias de epígrafes constituem um testemunho valioso da língua não literária de sua época e de seu local de origem; a sintaxe, a gramática podem ser trabalhadas usando estes documentos, que são autênticos restos da língua falada, registrando até eventuais erros de vocabulário. Neste grupo incluem-se aquelas de derivação popular, como algumas inscrições sepulcrais, e a maioria das inscrições em letras cursivas, como as tabuinhas com votos eleitorais, as famosas "maldições" conhecidas como tabellae defixionum, ou as frases escritas sobre vasos e outros objetos de uso doméstico bem como as inscrições pintadas em muros.

A grande maioria das inscrições eram incisas; as letras eram esculpidas na pedra, com uma incisão de secção reta e fundo côncavo, sendo por vezes cobertas com um pigmento colorido. Em monumentos públicos particularmente importantes as letras eram feitas 
em bronze ou em outro metal e afixadas com grampos ou pinos num sulco preparado. Podiam ser incisas em placas de bronze com um instrumento ponteagudo ou, mais excepcionalmente, fundidas com a própria placa, como na Lex de imperio Vespasiani, que se encontra no Museu Capitolino de Roma. Existiam ainda inscrições pintadas sobre uma superfície branca destinada a ser reutilizada várias vezes; além das parietais pintadas, as inscrições podiam ser compostas por tesserae em mosaicos. As marcas de fábrica eram fundidas em objetos feitos de argila, chumbo ou outro metal, fabricados em série, sendo as letras colocadas na matriz. Em tijolos, a marca aparece também em profundidade, colocada pelo sistema de imprimir um "selo" na argila ainda mole.

As inscrições mais elaboradas ou bem acabadas exigiam uma fase preparatória, em que o lapicida executava um esboço preliminar. Por vezes as letras capitais eram "guiadas", isto é, desenhadas com esquadro e seguindo uma medida padrão; outras vezes eram à mão livre. Não havia sinais indicativos de interrupção da palavra no final de uma linha; nas epígrafes mais cuidadas observava-se a divisão silábica; nas mais mal acabadas, a paginação era casual, sem observar as proporções entre a extensão da inscrição e a superfície a ser inscrita. Há casos em que o lapicida escreveu o final da palavra na borda lateral da placa.

As inscrições latinas mais antigas conservadas remontam aos séculos VII ou VI a.C. Da época arcaica, o cipo do Fórum ( CIL 12,1) consiste num regulamento sacral, em uma escrita do tipo bustrofédon. $\mathrm{O}$ vaso de Dueno contém uma inscrição grafitada num vaso de terracota (CIL 12,4). Estes textos constituem os primeiros testemunhos autênticos do uso da língua latina.

Uma fíbula de ouro encontrada numa tumba em Preneste, em 1871, apresenta uma inscrição da direita para a esquerda, com letras muito arcaicas, sendo o F o digama grego. Constitui um exemplo de "objeto falante": "Mânio me fez para Numasios (Numério)".

CIL 1 2, 3 (Roma, Museu de Vila Giulia).

Manios: med: fhe: fhaked: Numasioi

(Manius me fecit Numasio)

As palavras são separadas por dois pontos. Constam da inscrição o nome do ouríves e o nome da pessoa a quem a jóia era destinada ou do seu comitente. Esta é considerada uma das mais antigas inscrições latinas, remontando talvez ao século VII a.C.; no entanto, a sua autenticidade é contestada por alguns autores.

"As epígrafes são incluídas em diferentes categorias para facilitar seu estudo. São consideradas sacras as colocadas em altares, imagens, cipos ou estelas, sendo relativas a ofertas votivas; a própria inscrição por vezes se constitui na oferenda à divindade. As sepulcrais estão relacionadas a tumbas, podendo conter além do nome e a idade do morto, informações biográficas, meditações sobre a morte, disposições a respeito do sepulcro ou imprecações contra eventuais violadores.

Ainda hoje inscrições honorárias ou referentes a obras públicas podem facilmente ser lidas num passeio pelo centro histórico de Roma. São consideradas honorárias aquelas que tinham o objetivo de homenagear um indivíduo ainda em vida, ou mesmo um morto, desde que não estejam relacionadas com um sepulcro. Foram colocadas em monumentos honorários, em bases de estátuas, arcos, colunas. Podiam ser encomendadas pelo próprio personagem ou oferecidas por outros dedicantes: parentes, simples particulares ou, com frequência, por uma inteira comunidade que desejava homenagear um personagem representativo a quem deviam favores. Um exemplo de inscrição honorária encontra-se no arco 
construído pelo senado e povo romano, nas proximidades da Cúria do Senado, dedicado a Septímio Severo e aos seus dois filhos, Caracala e Geta, em 203.

CIL VI, 1033 (Roma).

Imp. Caes(ari) Lvcio Septimio M. fil(io) Severo Pio Pertinaci Avg(vsto) patri patriae Parthico Arabico et Parthico Adiabenico Pontific(i) Maximo tribvnic(ia) potest(e) XI Imp(eratori) XI co(n)s(vli) III Proco(n)s(uli) et Imp Caes(ari) M Avrelio Lfil(io) Antonino Avg(vsto) Pio Felici tribvnic(ia) potest(ate) VI co(n)s(vli) Proco(n)s(vli) p p optimis fortissimisque principibvs ob rem pvblicam restitvtam imperivmqve popvli Romani propagatvm insignibvs virtvtibvs eorvm domi forisque S(enatvs) $P($ opvlvs $) Q$ (ve) R(omanvs).

A dedicatória diz: “Ao imperador César Lúcio Septímio Severo, filho de Marco, Pio, Pertinaz, Augusto, pai da Pátria, Pártico Arábico e Pártico Adiabênico, Pontífice Máximo, com o poder tribunício pela $11^{\mathrm{a}}$. vez, aclamado imperador pela $11^{\mathrm{a}}$. vez, cônsul pela 3 a . vez, procônsul; e ao Imperador César Marco Aurélio Antonino, filho de Lúcio, Augusto, Pio, Feliz, com o poder tribunício pela $6^{\text {a }}$. vez, cônsul, procônsul, pai da pátria, ótimos e fortíssimos príncipes, por terem salvado o Estado e ampliado o domínio do povo romano, e pelas suas insignes virtudes, na pátria e no exterior, o Senado e o Povo romano". Após a morte de Septímio Severo, Caracala assassinou o irmão em 212 e o nome de Geta foi removido, sendo substituído pelas palavras p.p. optimis fortissimisqve principibvs. Como as letras eram de bronze, os furos dos pregos de metal permitiram reconstituir as palavras dedicadas ao César Geta, que tinham sido eliminadas: et P. Septimio L. fil. Getae nobiliss. Caesari.

Na outra extremidade da Via Sacra, no fórum, o arco de Tito exibe a inscrição:

CIL VI, 945 (Roma).

Senatvs popvlvsque Romanvs divo Tito divi Vespasiani f(ilio) Vespasiano Avgvisto

"O Senado e o povo romano ao divino Tito, filho do divino Vespasiano, Vespasiano Augusto"; a referência a Tito como "divino" indica que obviamente ele já estava morto quando a inscrição foi incisa. Portanto, o arco deve ser datado como sendo posterior ao ano de 81 e provavelmente é obra de Domiciano, irmão de Tito e filho de Vespasiano.

Ainda no fórum romano, no Casa das Vestais, encontramos outro exemplo de inscrição honorária, na base de uma estátua de Terência Flávula, Vestal Máxima, colocada por um escultor (fictus) do próprio templo e por um seu aprendiz.

CIL VI, 32413 (Roma, Fórum).

Terentiae Flavolae V(irgini) V(estali) Maximae Cn(aeus) Statilivs Menander fictor V V Cn(aei) Statili Cerdonis fictoris V V alumnvs.

No Atrium Vestae foram encontradas outras bases de estátuas da mesma Vestal que continham dedicatórias em honra desta personagem: uma delas feita pelo irmão Terêncio Genciano, pretor provavelmente do ano 209 d.C.; outra, dedicada pelo irmão Quinto Loliano Avito e uma terceira por Aurélio Júlio Balbilo, sacerdote do Sol; por meio desta última, depreende-se que em 215 d. C. Terência Flávula era Vestal Máxima. 
As inscrições relativas a obras públicas são abundantes, comemorativas da construção ou restauro de monumentos e edifícios públicos. Aparecem em fóruns, nas termas e aquedutos; em ambientes ligados à vida política, como a cúria do senado; em locais culturais, como bibliotecas, e em obras decorativas como fontes, arcos e obeliscos. Podem ter sido colocadas pela comunidade ou oferecidas por particulares, colégios e associações. Durante a República o cuidado com obras públicas era encargo de magistrados, como os cônsules; posteriormente foram também criados magistrados especiais como os curatores viarum para cuidar da manutenção de ruas e pontes.

Uma epígrafe desta categoria encontra-se na ponte Fabrício ou Quattro Capi que une a ilha Tiberina à margem do Tibre, no Campo de Marte, em Roma. Conhecemos por Díon Cássio (XXXVII, 45,3) a data de sua construção, em 62 a.C. Uma inscrição em grandes letras foi colocada nos blocos de pedra que formam as duas grandes arcadas da ponte, repetida em ambos os lados.

CIL 12, 751; VI, 1305 (Roma, Ponte Fabrício).

No arco da esquerda

L. Fabricivs C.f. cvr(ator) viar(vm) facivndvm coeravit eidemqve probaveit. Q. Lepidvs M'f. M. Lollivs M. $f$. Co(n)svles ex S(enatvs) C(onsvlto) probavervn[t]

A epígrafe superior, no arco do lado esquerdo, recorda o nome do construtor, Lúcio Fabrício, o curator viarum, ou seja, o magistrado encarregado das ruas e lugares públicos, que empreendeu a sua construção. Abaixo, em letras menores, uma segunda inscrição registra os nomes dos dois cônsules do ano 21 a.C., que por ordem do Senado encarregaram-se da restauração; é mencionada apenas a aprovação da obra. Talvez a ponte tivesse sido danificada pela inundação do Tibre em 23 a.C. (D. Cássio, LIII,33).

Se durante a República os grandes personagens da vida política já usavam inscrições com finalidade propagandística, durante o Império esta prática ampliou-se. Material abundante foi produzido pelos novos escalões do governo, inclusive por personagens muito próximas ao imperador. Assim, outra inscrição em edifício público que se pode ainda ler in loco é esta:

CIL VI, 896 (Roma, Panteão).

M(arcvs) Agrippa L(vci) f(ilivs) co(n)s(ul) tertivm fecit

Colocada na faixa sobre a arquitrave do Panteão, inclusive com função decorativa, a epígrafe registra o nome do cônsul: "Marcos Agripa, filho de Lúcio, cônsul pela terceira vez, construiu”. Marco Vipsânio Agripa, genro de Augusto, foi cônsul pela terceira vez em 27 a.C. e o Panteão foi inaugurado em 25 a.C. (Díon Cássio, LIII,27). O edifício foi reconstruído pelo imperador Adriano, segundo a História Augusta informa e é confirmado pelos selos laterícios e pelos elementos estruturais. A epígrafe, portanto, foi colocada por Adriano, apesar dele ser o construtor praticamente de um novo edifício e da cúpula; ele se notabilizou por nunca ter inscrito o próprio nome nas inúmeras construções que fez (Historia Augusta, Vita Hadriani, 19,9), preferindo manter os nomes originais dos antigos fundadores dos edifícios que restaurou.

Leis, decretos e senatus consulta fazem parte da epigrafia jurídica, existindo ainda Fastos, calendários e atas de reunião de colégios sacerdotais. Os marcos miliários e os cipos 
para demarcação de limites e das margens do Tibre formam uma categoria à parte. Nos últimos volumes do Corpus Inscriptionum Latinarum estão reunidas as inscrições em objetos variados de uso na vida privada, sob a rubrica Instrumentum domesticum: telhas, canos, tijolos, tesserae, colares de escravos e jóias. Constituem um importante instrumento para o conhecimento de aspectos da vida cotidiana das camadas populares e de suas relações com o governo imperial e com os grupos dirigentes.

Estas breves considerações e o exame de alguns exemplos remanescentes de inscrições tiveram por objetivo analisar a difusão do uso de textos escritos no mundo romano e a amplitude de seu emprego nos mais variados contextos e ambientes sociais, sendo capazes de oferecer um testemunho detalhado da Antigüidade clássica.

\section{Referências bibliográficas}

CALABI LIMENTANI, Ida. Epigrafia latina. 3. ed. Milano: Cisalpino-Goliardica, 1974.

CORBIER, Mireille. “L'écriture dans l'espace public romain”. In: L' Urbs. Espace urbain et histoire. Rome: École Française de Rome, 1987. p. 27-60. (Collection de L'École Française de Rome, 98).

CORPUS INSCRIPTIONUM LATINARUM (CIL) consilio et auctoritate Academiae litterarum Borussicae editum, Berolini.

POUCET, Jacques. "Réflexions sur l'écrit et l'écriture dans la Rome des premiers siècles". Latomus, t. 48, p. 285-311, 1989.

WUILLEUMIER, P. "La contribution de l'épigraphie latine à la connaissance de la civilisation romaine". Aufstieg und Niedergang der Römischen Welt. Berlin; New York: Walter de Gruyter, t. II, 1, p. 790-795, 1974.

CORASSIN, Maria Luiza. L'usage de l'écriture dans l'épigraphie latine. Classica. São Paulo, 11/12, 205-212, 1998/1999.

RÉSUMÉ: Rome connaît des multiples usages de l'écriture sous les formes plus diverses: usage public (textes politiques, administratives, religieux) mais aussi usage privé. L'utilisation intense des inscriptions constitue une caractéristique du monde romain, "la civilisation de l'épigraphie"; elles sont des documents originaux inestimables de la situation économique et sociale romaine.

MOTS-CLÉS: Rome; écriture; épigraphie. 